\title{
Shape of the association between preoperative hemoglobin level and postoperative outcomes in patients undergoing primary arthroplasty
}

\author{
George Grammatopoulos, \\ MBBS, DPhil \\ Daniel I. Mclsaac, MD, MPH \\ Paul E. Beaulé, MD \\ Carl van Walraven, MD
}

Accepted Feb. 4, 2021

\author{
Correspondence to: \\ G. Grammatopoulos \\ Division of Orthopaedic Surgery \\ The Ottawa Hospital - General Campus \\ CCW 1638, 501 Smyth Rd \\ Ottawa ON K1H 8L6 \\ ggrammatopoulos@toh.ca
}

Cite as: Can J Surg 2022 January 18; 65(1). doi: 10.1503/cjs.020720

\begin{abstract}
Background: The shape of the association between preoperative hemoglobin level and outcomes after primary arthroplasty has not been adequately described. This study aimed to characterize the association between preoperative hemoglobin level and important outcomes after primary hip and knee arthroplasty and how this association is influenced by other key confounders.
\end{abstract}

Methods: Using de-identified, population-based health administrative data for Ontario housed at ICES, we identified all primary hip and knee arthroplasty procedures performed in Ontario between April 2007 and March 2017. Preoperative hemoglobin level, age, sex, Charlson Comorbidity Index score, American Society of Anesthesiologists score, preadmission living status, Hospital-patient One-year Mortality Risk (HOMR) score, and serum sodium and creatinine levels were extracted. All relevant postoperative outcomes that could be measured accurately were identified. We performed multivariable logistic regression and restricted cubic splines analyses.

Results: A total of 188176 patients clustered within 532 surgeons were studied. The adjusted likelihood of transfusion increased notably and progressively when the preoperative hemoglobin level was below $135 \mathrm{~g} / \mathrm{L}$; duration of surgery, patient age and HOMR score amplified this association. Risk of postoperative admission to critical care showed a linear association with preoperative hemoglobin level. Risks of unplanned 30-day emergency department visit, 30-day readmission and 1-year all-cause mortality showed curvilinear associations with baseline hemoglobin level, with risks being notably greater as the level deviated from $137 \mathrm{~g} / \mathrm{L}$ to $141 \mathrm{~g} / \mathrm{L}$.

Conclusion: Preoperative hemoglobin levels, both high and low, were independently significantly associated with primary arthroplasty outcomes, and levels at which outcome risks started to increase exceeded threshold values commonly used to define "normal." Preoperative hemoglobin level should be considered in future bundled payment models that aim to account for case-mix when grading postarthroplasty outcomes.

Contexte : La forme que prend le lien entre le taux d'hémoglobine préopératoire et l'issue de l'arthroplastie primaire n'a pas été adéquatement décrite. Cette étude visait à caractériser le lien entre les taux d'hémoglobine préopératoires et certains paramètres importants après l'arthroplastie primaire de la hanche et du genou, et à analyser l'influence de certains facteurs de confusion clés sur ce lien.

Méthodes : À partir de données administratives anonymisées sur la santé des populations en Ontario hébergées par l'ICES, nous avons recensé toutes les interventions pour arthroplastie primaire de la hanche et du genou effectuées en Ontario entre avril 2007 et mars 2017. Nous en avons extrait les taux d'hémoglobine préopératoires, l'âge, le sexe, l'indice de comorbidité de Charlson, le score de l'American Society of Anesthesiologists, la situation de vie préadmission, le score HOMR (Hospital-patient One-Year Mortality Risk) et les taux sériques de sodium et de créatinine. Nous avons identifié tous les paramètres postopératoires pertinents qu'il était possible de mesurer avec précision. Nous avons procédé à des analyses de régression logistique multivariées et au calcul des splines cubiques restreintes.

Résultats : En tout, nous avons étudié 188176 patients répartis entre 532 chirurgiens. La probabilité ajustée de transfusion augmentait nettement et progressivement lorsque les taux d'hémoglobine préopératoires étaient inférieurs à $135 \mathrm{~g} / \mathrm{L}$; la durée de la chirurgie, l'âge du patient et le score HOMR ont amplifié ce lien. Le risque d'admission dans une unité de soins intensifs après la chirurgie a été en lien linéaire avec les taux d'hémoglobine préopératoires. Les risques de consultation imprévue aux 
urgences dans les 30 jours, la réhospitalisation dans les 30 jours et la mortalité de toute cause à 1 an ont montré des liens curvilinéaires avec les taux d'hémoglobine au départ, les risques étant sensiblement plus élevés lorsque les taux s'éloignaient des valeurs de $137 \mathrm{~g} / \mathrm{L}$ à $141 \mathrm{~g} / \mathrm{L}$.

Conclusion : Les taux d'hémoglobine préopératoires élevés et bas ont été indépendamment en lien significatif avec certains paramètres post-arthroplastie primaire, et les taux à partir desquels le risque de survenue des paramètres mesurés commençait à augmenter excédaient les valeurs seuils communément considérées normales. Au moment d'évaluer les paramètres post-arthroplastie, les taux d'hémoglobine préopératoires doivent entrer en ligne de compte dans les futurs modèles d'évaluation monétaire groupée qui visent à représenter les cas traités.

$\mathbf{R}$ ates of primary hip and knee arthroplasty are increasing continually; more than 1.4 million primary joint replacement operations were performed in North America in 2019 alone., ${ }^{1,2}$ Although advancement in the performance of these procedures has occurred, ${ }^{3}$ the incidence of peroperative complications remains consequential, varying between $6 \%$ and $19 \% .4,5$ Preoperative patient optimization may improve the body's "reserve" and ability to recover after surgery.

Hemoglobin level is a modifiable preoperative factor that is immediately relevant to arthroplasty. Preoperative anemia is relatively common, with a documented prevalence of $21 \%-35 \%$ that has remained unchanged over the years. ${ }^{67}$ Furthermore, arthroplasty is associated with considerable blood loss, even with contemporary preventive measures in place. ${ }^{8-12}$ As a result, more than $90 \%$ of patients are anemic after arthroplasty. ${ }^{13,14}$

Anemia before arthroplasty has been associated with increased transfusion risk, ${ }^{13,15,16}$ morbidity, mortality and length of stay. ${ }^{4,5,17-26}$ However, these associations have been analyzed almost exclusively after categorization of preoperative hemoglobin levels (i.e., grouping patients with or without anemia, however defined). Categorization of continuous variables decreases the power of analyses to identify associations substantially and leads to information loss. ${ }^{27}$

In addition, the shape of the association between preoperative hemoglobin level and outcomes has not been adequately described. For example, it is unclear whether supranormal hemoglobin levels (i.e., polycythemia) are protective (as they could reduce transfusion risk) or a potential risk factor (owing to a possibly increased risk of venous thromboembolism). Therefore, analyzing the continuous, but possibly nonlinear, association of preoperative hemoglobin level with outcomes could help to identify levels at which outcome risks threaten the procedure's utility, as well as identify patients in need of hematologic optimization. Furthermore, to our knowledge, the influence of other factors on the association between preoperative hemoglobin level and outcome has not been examined to any substantial degree.

The aims of this population-based study were to characterize the association between hemoglobin level and a number of outcomes - red cell transfusion, postoperative admission to a critical care unit, unplanned 30-day emergency department visit, unplanned 30-day hospital readmission and 1-yr all-cause mortality - after primary arthroplasty and describe the characteristics of the association; and test for any interactions of this association with other key confounders influencing outcome.

\section{Methods}

\section{Study design and data sources}

This was a retrospective cohort study using de-identified, population-based health administrative data for Ontario, Canada, housed at ICES, a publicly funded, independent research organization. The following data sets were linked deterministically by means of encrypted patient health card numbers in order to obtain the information necessary for this study: Discharge Abstract Database, Ontario Laboratory Information System (OLIS), Registered Persons Database, National Ambulatory Care Reporting System, Ontario Health Insurance Plan and Continuing Care Reporting System (Appendix 1, available at www.canjsurg.ca/lookup/doi/10.1503/cjs.020720/ tab-related-content). The study was approved by ICES and was legally exempt from research ethics board review owing to the de-identified nature of the data.

\section{Study cohort}

We searched the Discharge Abstract Database from Apr. 1, 2007, to Mar. 31, 2017, to identify all elective admissions with total hip arthroplasty (Canadian Classification of Health Intervention codes 1VA53LAPN and 1VA53PNPN), including resurfacing arthroplasty, and total knee arthroplasty (Canadian Classification of Health Intervention codes starting with 1VG53) as the primary procedure. We linked to OLIS to identify all hemoglobin tests conducted in these patients; patients with no hemoglobin measured in the year before arthroplasty were excluded. To ensure that the unit of analysis was the patient, we limited inclusion to the first procedure meeting the inclusion criteria during the study period for 
individual patients and excluded patients who had undergone arthroplasty in the 6 months before their index procedure. We included the latter exclusion criterion since recent surgery is associated with anemia ${ }^{13,14}$ and leads to selection bias.

\section{Hemoglobin level}

We identified all hemoglobin measures for each patient in the year before his or her operation from OLIS. We recorded the final preoperative hemoglobin level and the number of days before the operation that it was measured.

\section{Outcomes}

We identified all relevant postoperative outcomes that we could measure accurately using our data; ${ }^{28}$ we did not prioritize these outcomes (i.e., none was nominally chosen as the "primary outcome"). In-hospital outcomes included transfusion of packed red cells and transfer to a critical care unit. Postdischarge outcomes included unplanned emergency department visits and hospital readmissions within 30 days of discharge from hospital, and death from any cause within 1 year of surgery. We chose the 30 -day period since this is typical of the literature on readmission. ${ }^{18} \mathrm{We}$ identified all outcomes before analyzing the data.

\section{Covariables}

We determined patient age, sex, year of surgery, Charlson Comorbidity Index score ${ }^{29}$ (using a 1-year look-back period with comorbidity coding criteria from Quan and colleagues $^{30}$ and score weights from Schneeweiss and colleagues ${ }^{31}$ ), number of hospital admissions in the previous year and procedure factors (laterality, anesthetic technique and operation duration) from the Discharge Abstract Database. We retrieved each patient's serum sodium and creatinine levels closest in time to his or her operation from OLIS because a significant association between hyponatremia $\mathrm{a}^{32-37}$ and decreased renal function ${ }^{38}$ and mortality has been described. We determined the American Society of Anesthesiologists Physical Status score from Ontario Health Insurance Plan data. ${ }^{39}$ We determined preadmission living status (independent, inpatient rehabilitation, home care, nursing home [i.e., long-term care institution] or chronic care hospital [i.e., complex continuing care]) from the Continuing Care Reporting System. We determined death risk using the Hospitalpatient One-year Mortality Risk (HOMR) score. This model combines values for 12 covariables regarding patient demographic characteristics, health burden and acuity of illness to create a score that is highly discriminative (C-statistic 0.89) and well calibrated for 1-year allcause death risk. ${ }^{40}$ It has been validated externally with administrative data ${ }^{41}$ and primary data. ${ }^{42}$

\section{Statistical analysis}

We used SAS 9.4 (SAS Institute) for all analyses. We used multivariable logistic regression accounting for the clustering of patients within surgeon to model the independent association of each covariable with each outcome (PROC GLIMMIX). In this generalized linear mixed model, the surgeon was treated as the random-effects term, and all other factors were treated as fixed effects. We reasoned that several of the outcomes - notably receipt of transfusion and critical care use - might be strongly dependent on surgeon-specific practice patterns; as such, accounting for these issues by clustering patients within surgeon could explain much variation in the data.

Before analyzing the data, we specified all covariables to be included in the models; no post hoc or variable selection based on inferential testing was used. All continuous variables were centred before modelling. Those included age, sex, HOMR score, sodium level, baseline estimated glomerular filtration rate, type of procedure (hip or knee), American Society of Anesthesiologists score, type of anesthetic (spinal, general, combined or other), laterality (unilateral or bilateral) of procedure and duration of surgery. For patients with missing sodium or serum creatinine levels, we imputed median values of the cohort, since this returns results that are less biased than if normal values are used for simple imputation. ${ }^{43}$ We converted serum creatinine values to a baseline estimated glomerular filtration rate using the CKD-EPI (Chronic Kidney Disease Epidemiology Collaboration) equation. ${ }^{44} \mathrm{We}$ used restricted cubic splines to model the independent association of all continuous variables (including their interactions) with each outcome using 5 knots for all variables except those with restricted distributions, including sodium (3 knots) and the interaction between hemoglobin with arthroplasty type ( 3 knots) and with patient sex ( 2 knots). We used restricted cubic splines because the main effect estimate is continuous and we wanted to identify any potential nonlinear relations present.

\section{REsults}

We identified 364480 elective hospital admissions between Apr. 1, 2007, and Mar. 31, 2017, in which total hip or knee arthroplasty was coded as the primary procedure. Of the 364480 patients, 131932 were excluded because no preoperative hemoglobin value had been registered in OLIS, 43004 were excluded because the patient was already included in the study, and 1368 were excluded because they had undergone arthroplasty within the previous 6 months. The remaining 188176 patients, clustered within 532 surgeons (median number of patients per surgeon 176.5, interquartile range 2.5-616), formed the study's cohort. The proportion of arthroplasty procedures excluded because of lack of a hemoglobin value in OLIS 
varied substantially over time owing to temporal changes in OLIS coverage (77.3\% in 2008 v. $8.8 \%$ in 2016).

The cohort basic demographic characteristics are presented in Table 1. Almost two-thirds of operations (120 273 [63.9\%]) were knee arthroplasty procedures.
Patients were upper-middle-aged (mean age $67.8 \mathrm{yr}$ [standard deviation $10.2 \mathrm{yr}$ ) and predominantly female (112009 [59.5\%]). The mean hemoglobin level was $136.2 \mathrm{~g} / \mathrm{L}$ (standard deviation $14.2 \mathrm{~g} / \mathrm{L}$ ). Most patients (96 228 [51.1\%]) had their preoperative hemoglobin level

Table 1. Characteristics of patients who underwent primary hip or knee arthroplasty in Ontario, Apr. 1, 2007, to Mar. 31, 2017

\begin{tabular}{|c|c|c|c|}
\hline \multirow[b]{2}{*}{ Characteristic } & \multicolumn{3}{|c|}{ No. (\%) of patients* } \\
\hline & $\begin{array}{c}\text { Total } \\
n=188176\end{array}$ & $\begin{array}{l}\text { Hip arthroplasty } \\
\quad n=67903\end{array}$ & $\begin{array}{c}\text { Knee arthroplasty } \\
n=120273\end{array}$ \\
\hline \multicolumn{4}{|l|}{ Demographic } \\
\hline Age, mean $\pm S D, y r$ & $67.8 \pm 10.2$ & $67.6 \pm 11.5$ & $67.9 \pm 9.4$ \\
\hline Female sex & $112009(59.5)$ & $37575(55.3)$ & $74434(61.9)$ \\
\hline Charlson Comorbidity Index score $>0$ & $44613(23.7)$ & 14455 (21.3) & $30158(25.1)$ \\
\hline$\geq 1$ admissions in previous year & $5881(3.1)$ & $2931(4.3)$ & $2950(2.4)$ \\
\hline \multicolumn{4}{|l|}{ Preadmission living status } \\
\hline Independent & $154364(82.0)$ & $52725(77.6)$ & $101639(84.5)$ \\
\hline Inpatient rehabilitation & $58(0.0)$ & $46(0.1)$ & $12(0.0)$ \\
\hline Home care & $32766(17.4)$ & $14587(21.5)$ & $18179(15.1)$ \\
\hline Nursing home & $933(0.5)$ & $505(0.7)$ & $428(0.4)$ \\
\hline Chronic care hospital & $55(0.0)$ & $40(0.1)$ & $15(0.0)$ \\
\hline \multicolumn{4}{|l|}{ Risk factors } \\
\hline HOMR score, median (IQR) & $17(14-21)$ & $21(18-24)$ & $15(13-18)$ \\
\hline 1 -yr expected death risk $>0.2 \%$ & $48979(26.0)$ & $34645(51.0)$ & $14334(11.9)$ \\
\hline $\begin{array}{l}\text { No. of hemoglobin measures in previous year, } \\
\text { median (IQR) }\end{array}$ & $2(1-3)$ & $2(1-3)$ & $2(1-3)$ \\
\hline Most recent hemoglobin level, mean $\pm \mathrm{SD}, \mathrm{g} / \mathrm{L}$ & $136.2 \pm 14.2$ & $136.2 \pm 15.0$ & $136.1 \pm 13.7$ \\
\hline $\begin{array}{l}\text { Days from most recent hemoglobin measure to } \\
\text { surgery, median (IQR) }\end{array}$ & $30(14-127)$ & $30(14-129)$ & $29(14-126)$ \\
\hline Sodium level, mean $\pm \mathrm{SD}, \mathrm{mmol} / \mathrm{L}$ & $139.9 \pm 2.6$ & $139.9 \pm 2.6$ & $140.0 \pm 2.6$ \\
\hline Sodium level not measured & $25774(13.7)$ & 9901 (14.6) & $15873(13.2)$ \\
\hline Creatinine level, mean $\pm \mathrm{SD}, \mu \mathrm{mol} / \mathrm{L}$ & $77.9 \pm 27.4$ & $78.4 \pm 29.5$ & $77.7 \pm 26.2$ \\
\hline Creatinine level not measured & $10067(5.3)$ & $3873(5.7)$ & $6194(5.1)$ \\
\hline \multicolumn{4}{|l|}{ ASA score } \\
\hline $1-2$ & 63566 (33.8) & 24779 (36.5) & 38787 (32.2) \\
\hline 3 & $109721(58.3)$ & $37673(55.5)$ & $72048(59.9)$ \\
\hline 4 & $14858(7.9)$ & $5432(8.0)$ & $9426(7.8)$ \\
\hline 5 & $31(0.0)$ & $19(0.0)$ & $12(0.0)$ \\
\hline \multicolumn{4}{|l|}{ Operation } \\
\hline \multicolumn{4}{|l|}{ Laterality } \\
\hline Left & $87125(46.3)$ & $30900(45.5)$ & $56225(46.7)$ \\
\hline Right & $97742(51.9)$ & $36778(54.2)$ & $60964(50.7)$ \\
\hline Bilateral/unspecified & $3309(1.7)$ & $225(0.3)$ & $3084(2.6)$ \\
\hline \multicolumn{4}{|l|}{ Anesthetic technique } \\
\hline Spinal & $148942(79.2)$ & $52599(77.5)$ & $96343(80.1)$ \\
\hline General & $31271(16.6)$ & $12525(18.4)$ & $18746(15.6)$ \\
\hline Combined & $5445(2.9)$ & $1931(2.8)$ & $3514(2.9)$ \\
\hline Other & 2518 (1.3) & $848(1.2)$ & $1670(1.4)$ \\
\hline Length of operation, median (IQR), h & $2(2-2)$ & $2(2-2)$ & $2(1-2)$ \\
\hline Length of stay, median (IQR), d & $3(3-4)$ & $3(3-4)$ & $3(3-4)$ \\
\hline \multicolumn{4}{|l|}{ Outcomes } \\
\hline Red cell transfusion & 6405 (3.4) & $2739(4.0)$ & $3666(3.0)$ \\
\hline Death in hospital & $245(0.1)$ & $114(0.2)$ & $131(0.1)$ \\
\hline Postoperative critical care & $5035(2.7)$ & $1997(2.9)$ & $3038(2.5)$ \\
\hline Unplanned 30-d emergency department visit & $26975(14.3)$ & $8773(12.9)$ & $18202(15.1)$ \\
\hline Unplanned 30-d hospital readmission & $5576(3.0)$ & $2157(3.2)$ & $3419(2.8)$ \\
\hline Death within 1 yr & $2035(1.1)$ & $987(1.5)$ & $1048(0.9)$ \\
\hline
\end{tabular}


measured within a month of undergoing primary arthroplasty. Spinal anesthesia was the most common anesthetic technique (148 942 procedures [79.2\%]). Operations lasted a median of 1.75 hours, and patients remained in hospital a median of 3 days. Death in hospital was rare (245 patients $[0.1 \%])$; the risk was significantly higher with hip arthroplasty $(114 / 67903[0.2 \%])$ than with knee arthroplasty $(131 / 120273[0.1 \%])\left(\chi^{2}=11.6, p<0.001\right)$.

The findings of the logistic regression models, including the performance of the model, are summarized in Table 2. After adjustment for all other covariates in the model, there was no independent association of year and type of anesthesia with outcome for any of the variables. A more detailed presentation of the performance is provided in Appendix 1.

\section{Outcomes}

\section{Red cell transfusion}

The adjusted likelihood of transfusion was strongly associated with preoperative hemoglobin level, increasing notably and progressively when the level fell below $135 \mathrm{~g} / \mathrm{L}$

\section{Table 2. Summary of logistic regression models for all outcomes*}

\begin{tabular}{|c|c|c|c|c|c|}
\hline \multirow[b]{2}{*}{ Variable } & \multicolumn{5}{|c|}{ Outcome } \\
\hline & Red cell transfusion & $\begin{array}{c}\text { Postoperative critical } \\
\text { care }\end{array}$ & $\begin{array}{l}\text { Unplanned } 30-d \\
\text { emergency department } \\
\text { visit }\end{array}$ & $\begin{array}{l}\text { Unplanned 30-d hospital } \\
\text { readmission }\end{array}$ & 1-yr all-cause mortality \\
\hline \multicolumn{6}{|c|}{ Type III $p$ value for splined variables } \\
\hline Age & 0.0 & 0.0 & 0.0 & 0.0 & 0.0 \\
\hline HOMR score & 0.0 & 0.0 & 0.0 & 0.0 & 0.0 \\
\hline Sodium level & $<0.001$ & 0.9 & 0.04 & $<0.001$ & $<0.001$ \\
\hline eGFR & 0.02 & 0.001 & 0.03 & 0.0 & 0.0 \\
\hline Duration of surgery & 0.0 & 0.0 & 0.0 & 0.0 & 0.6 \\
\hline Hemoglobin level & 0.0 & 0.0 & 0.004 & $<0.001$ & 0.0 \\
\hline$\times$ Age & 0.004 & 0.001 & 0.08 & 0.09 & 0.1 \\
\hline x HOMR score & $<0.001$ & 0.0 & 0.2 & 0.7 & 0.6 \\
\hline$x$ Sodium level & 0.02 & 0.6 & 0.2 & 0.3 & 0.05 \\
\hline$x$ eGFR & 0.4 & 0.9 & 0.2 & 0.4 & 0.09 \\
\hline$x$ Duration of surgery & 0.0 & $<0.001$ & 0.1 & 0.03 & 1.0 \\
\hline$x \operatorname{Sex}$ & 0.02 & 0.2 & 0.3 & 0.7 & 0.05 \\
\hline$x$ Knee & 0.06 & 0.0 & 0.04 & 0.4 & 0.2 \\
\hline \multicolumn{6}{|c|}{ Adjusted OR (95\% Cl) for nonsplined variables } \\
\hline Knee & $0.75(0.68-0.84)$ & $2.51(2.26-2.78)$ & $1.51(1.44-1.59)$ & $1.23(1.11-1.35)$ & $1.43(1.21-1.70)$ \\
\hline Female sex & $1.20(1.11-1.30)$ & $0.82(0.76-0.87)$ & $0.87(0.85-0.90)$ & $0.81(0.76-0.86)$ & $0.69(0.62-0.77)$ \\
\hline \multicolumn{6}{|l|}{ ASA score } \\
\hline $1-2$ & Ref & Ref & Ref & Ref & Ref \\
\hline 3 & $1.03(0.97-1.10)$ & $2.23(2.04-2.43)$ & $1.13(1.10-1.16)$ & $1.42(1.33-1.52)$ & $1.76(1.53-2.02)$ \\
\hline $4-5$ & $1.17(1.05-1.30)$ & $5.44(4.91-6.04)$ & $1.22(1.16-1.28)$ & $1.88(1.71-2.08)$ & $3.37(2.86-3.96)$ \\
\hline Year & $0.96(0.87-1.06)$ & $0.92(0.84-1.02)$ & $1.00(0.95-1.04)$ & $1.05(0.96-1.15)$ & $1.04(0.89-1.21)$ \\
\hline Bilateral & $3.16(2.67-3.73)$ & $1.80(1.43-2.27)$ & $0.65(0.57-0.73)$ & $0.84(0.66-1.06)$ & $0.94(0.57-1.55)$ \\
\hline \multicolumn{6}{|l|}{ Anesthetic technique } \\
\hline Spinal & Ref & Ref & Ref & Ref & Ref \\
\hline General & $1.01(0.94-1.08)$ & $1.03(0.96-1.11)$ & $0.98(0.94-1.01)$ & $1.10(1.02-1.18)$ & $1.04(0.93-1.17)$ \\
\hline Combined & $1.08(0.92-1.28)$ & $0.85(0.71-1.02)$ & $0.99(0.92-1.07)$ & $1.17(1.00-1.36)$ & $0.82(0.61-1.09)$ \\
\hline Other & $1.19(0.98-1.46)$ & $0.86(0.67-1.11)$ & $0.96(0.85-1.07)$ & $0.94(0.74-1.19)$ & $0.82(0.55-1.22)$ \\
\hline \multicolumn{6}{|c|}{ Model performance } \\
\hline $\begin{array}{l}\text { Nagelkerke } R^{2} \text { statistic, } \\
\% \dagger\end{array}$ & 41.4 & 14.1 & 1.6 & 4.8 & 16.4 \\
\hline C-statisticł & 0.939 & 0.790 & 0.575 & 0.674 & 0.814 \\
\hline $\begin{array}{l}\text { Hosmer-Lemeshow } \\
p \text { value§ }\end{array}$ & 0.0 & 0.0 & 0.05 & 0.3 & 0.8 \\
\hline $\begin{array}{l}\text { ASA }=\text { American Society of } \\
\text { Ref }=\text { reference. } \\
\text { *All continuous variables anc } \\
\text { level) are not presented, rep } \\
\text { †Nagelkerke } R^{2} \text { statistic (ran } \\
\text { fC-statistic (range } 0-1 \text { ) meas } \\
\text { \$Hosmer-Lemeshow p valu }\end{array}$ & $\begin{array}{l}\text { hesiologists; } \mathrm{Cl}=\text { confide } \\
\text { interactions were expres } \\
\text { instead by the } p \text { value of } \\
0-100 \% \text { provides the pro } \\
\text { the model's ability to disc }\end{array}$ & $\begin{array}{l}\text { terval; } \text { eGFR = estimated } g \\
\text { the models with the use } \\
\text { variable's independent asso } \\
\text { on of all variation in data exp } \\
\text { ate between patients with a }\end{array}$ & $\begin{array}{l}\text { omerular filtration rate; HOMR } \\
\text { natural cubic splines. Therefor } \\
\text { iation with the outcome. For ca } \\
\text { ained by the model. } \\
\text { hd without the outcome. } \\
\text { likelihood deviates significantly }\end{array}$ & $\begin{array}{l}\text { Hospital-patient One-year Mor } \\
\text { parameter estimates ( } n=4 \text { fo } \\
\text { goric variables, adjusted OR n }\end{array}$ & $\begin{array}{l}\text { Risk; OR = odds ratio; } \\
\text { ch variable except sodium } \\
95 \% \mathrm{Cl} \text { is presented. }\end{array}$ \\
\hline
\end{tabular}


(Figure 1). Factors exaggerating this association included duration of surgery, patient age and HOMR score. At higher baseline hemoglobin levels, transfusion was significantly more likely with longer procedures; however, this progressive pattern diminished as baseline hemoglobin values decreased owing to the strong interaction term between hemoglobin value and duration of surgery (Table 2).

\section{Postoperative critical care}

The likelihood of postoperative admission to a critical care unit increased significantly as baseline hemoglobin level decreased (Figure 2). Critical care admission was notably more likely in younger patients and in those with higher HOMR scores, a feature especially notable at lower hemoglobin levels (Table 2); however, the degree of association was similar for the different age and HOMR score percentiles.

\section{Unplanned 30-day emergency department visit}

Baseline hemoglobin level was independently associated with the risk of an unplanned 30-day emergency department visit (Table 2), with a notable concave-up formation;

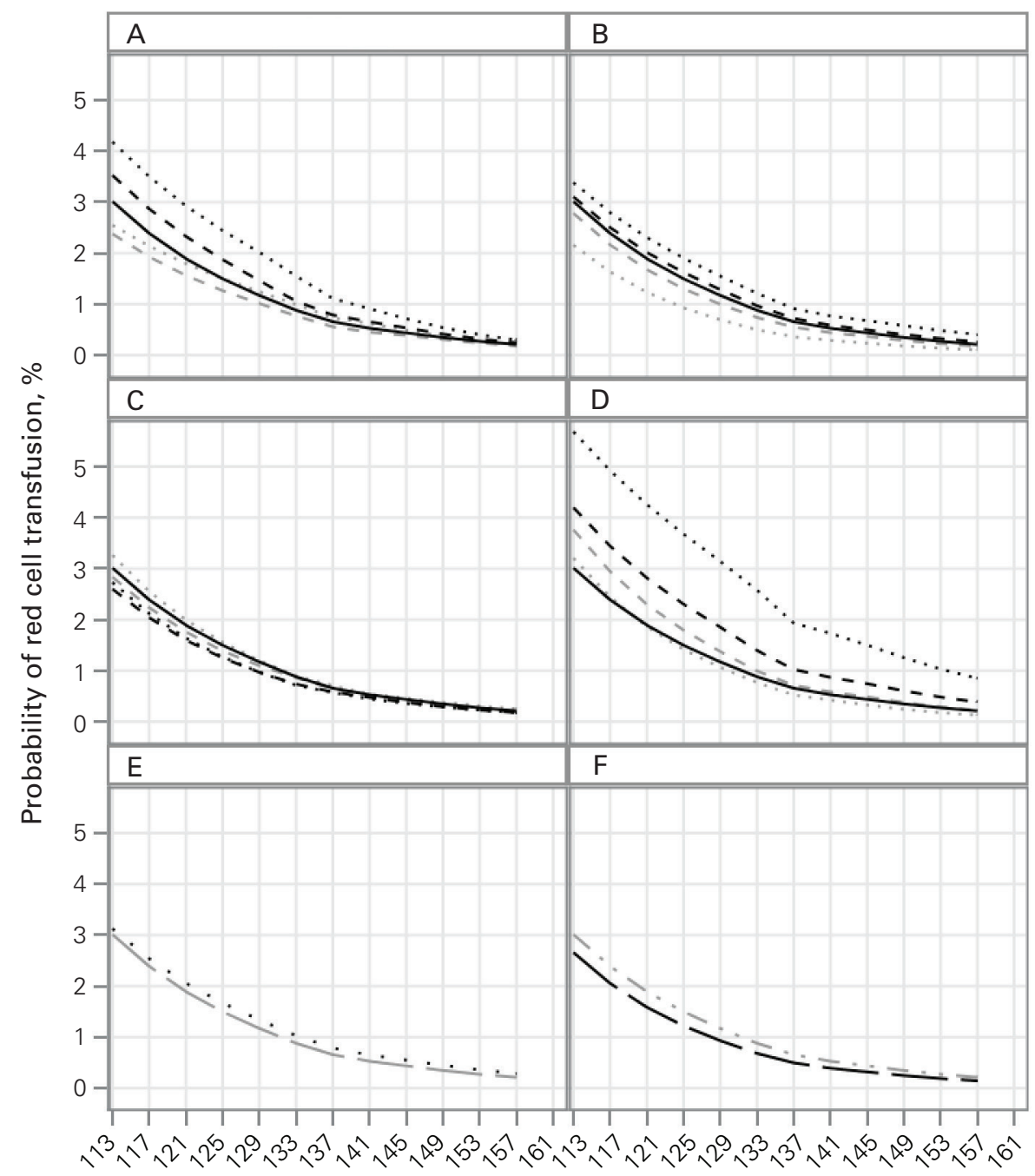

Hemoglobin level before arthroplasty, g/L

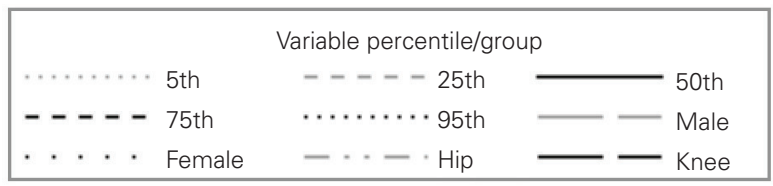

Fig. 1. Association between preoperative hemoglobin level and probability of red cell transfusion by age (A), Hospital-patient Oneyear Mortality Risk score (B), estimated glomerular filtration rate (C), duration of surgery (D), sex (E) and joint (F). Percentile values for each continuous variable are presented in Appendix 1, Table S1. All results are adjusted for the covariables presented in Table 2. 
its nadir occurred at hemoglobin levels around $140 \mathrm{~g} / \mathrm{L}$ and increased at levels both above and below (Figure 3). This association was not importantly influenced by the other covariables (Table 2).

\section{Unplanned 30-day hospital readmission}

The risk of unplanned 30-day hospital readmission had a curvilinear relation with baseline hemoglobin being notably more likely as baseline hemoglobin levels deviated from normal (Figure 4). The association between hemoglobin values and readmission risk did not vary notably with other covariables; however, the degree of association was greater as HOMR score increased, in male patients and in knee arthroplasty.

\section{One-year all-cause mortality}

Baseline hemoglobin level was strongly associated with the risk of 1-year all-cause mortality (Table 2), also with a distinct curvilinear pattern (Figure 5). This risk was not modulated notably by the other covariables (Table 2). The risk of death was most strongly associated with HOMR score.

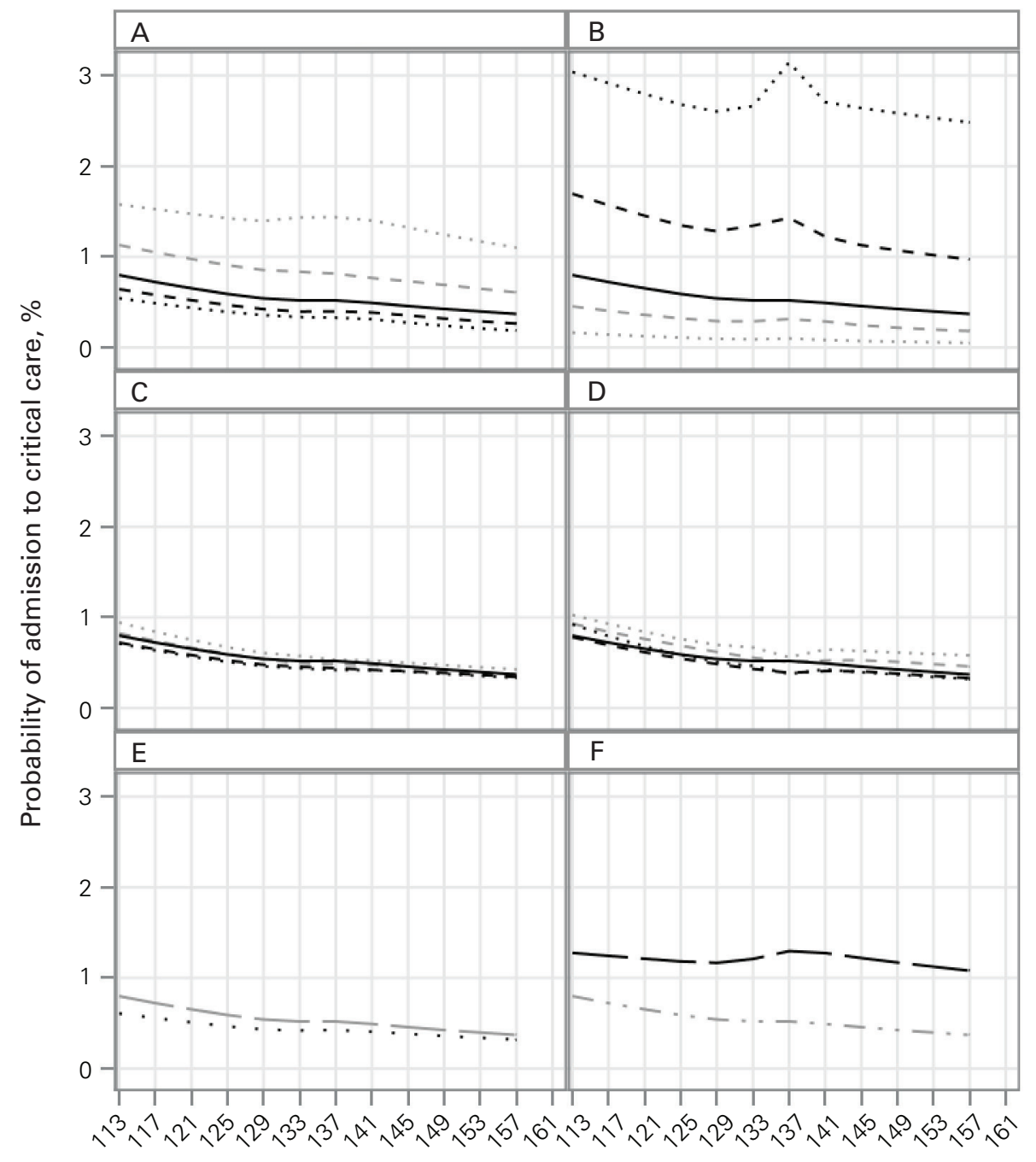

Hemoglobin level before arthroplasty, g/L

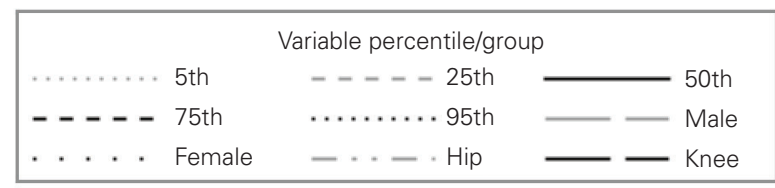

Fig. 2. Association between preoperative hemoglobin level and probability of postoperative admission to a critical care unit by age (A), Hospital-patient One-year Mortality Risk score (B), estimated glomerular filtration rate (C), duration of surgery (D), sex (E) and joint (F). All results are adjusted for the covariables presented in Table 2. 


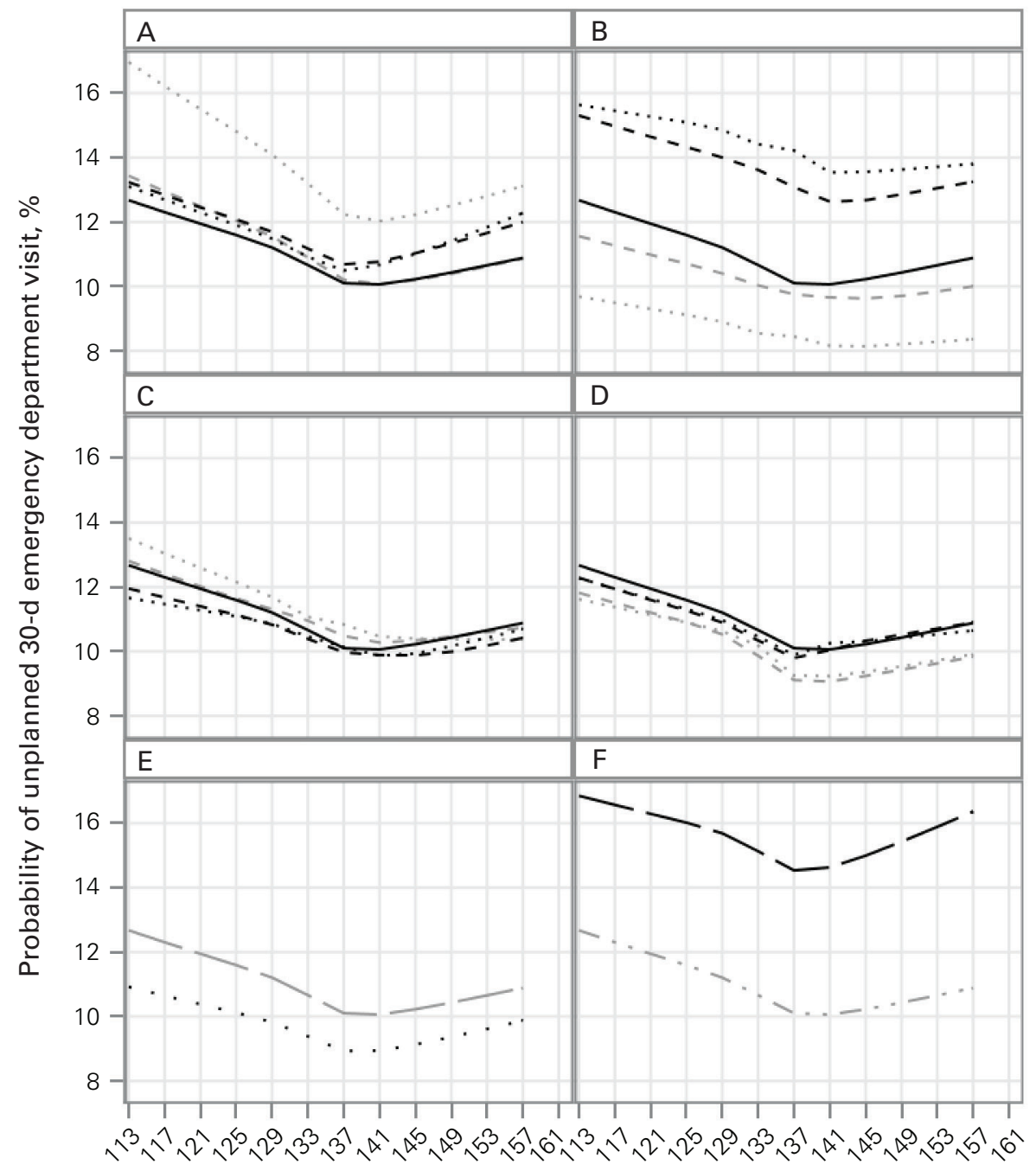

Hemoglobin level before arthroplasty, g/L

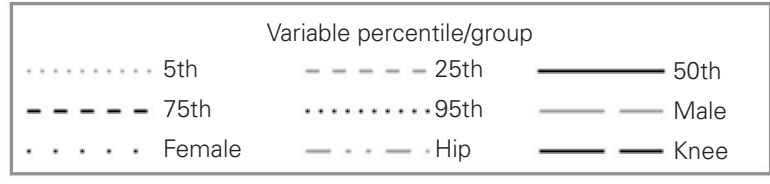

Fig. 3. Association between preoperative hemoglobin level and probability of unplanned 30-day emergency department visit by age (A), Hospital-patient One-year Mortality Risk score (B), estimated glomerular filtration rate (C), duration of surgery (D), sex (E) and joint (F). All results are adjusted for the covariables presented in Table 2.

\section{Discussion}

In this retrospective population-based study of more than 188000 patients who underwent primary arthroplasty, we found that preoperative hemoglobin levels, both high and low, were significantly associated with important outcomes after primary arthroplasty. After adjustment for key confounders, preoperative hemoglobin level was associated with the risk of red cell transfusion, postoperative critical care admission, unplanned 30-day emergency department visit, unplanned 30-day hospital readmission and 1-year all-cause mortality. Furthermore, we found that preoperative hemoglobin values at which outcome risks started to increase exceeded threshold values commonly used to define "normal" hemoglobin levels. We also found that an elevated preoperative hemoglobin level was associated with increased risk of postdischarge complications.

Based on these findings, we suggest that preoperative hemoglobin level can be a reliable patient risk stratification tool. Considering that the risk of red cell transfusion was notably low when the preoperative hemoglobin value 


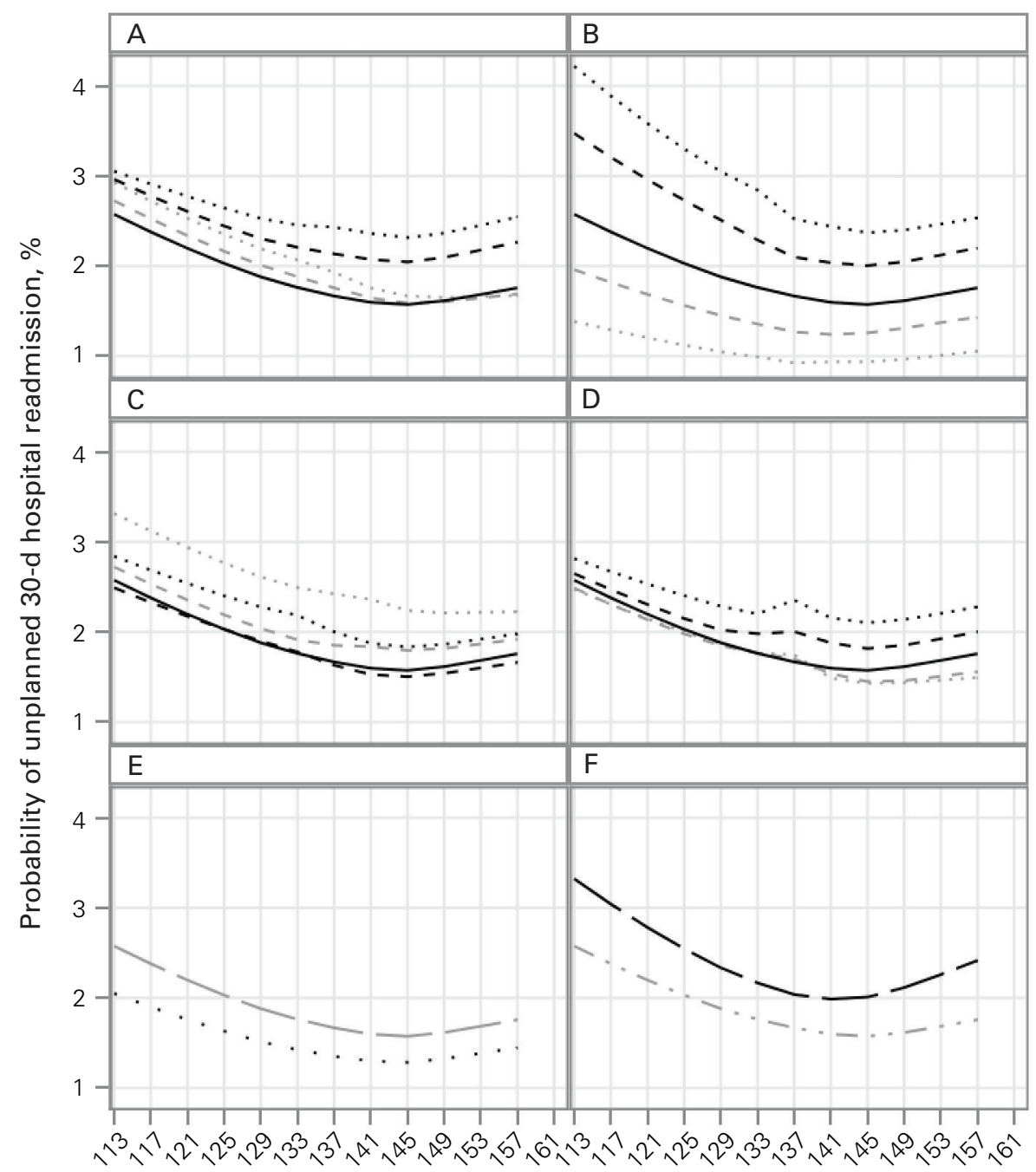

Hemoglobin level before arthroplasty, g/L

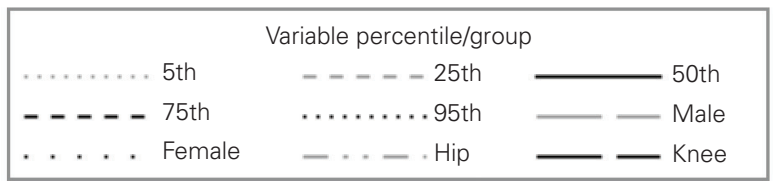

Fig. 4. Association between preoperative hemoglobin level and probability of unplanned 30-day hospital readmission by age (A), Hospital-patient One-year Mortality Risk score (B), estimated glomerular filtration rate (C), duration of surgery (D), sex (E) and joint (F). All results are adjusted for the covariables presented in Table 2.

exceeded $135 \mathrm{~g} / \mathrm{L}$, we recommend that type and cross matching may not be indicated in such patients, especially when surgery is not expected to be complex. Given the significant association of hemoglobin level with all postoperative outcomes measured in this study, preoperative hemoglobin level should be considered in future bundled payment models that aim to account for case-mix when grading postarthroplasty outcomes.

In contrast to most previous analyses of the association between preoperative hemoglobin value and arthroplasty outcomes (Table 3), we did not categorize hemoglobin values. This allowed us to identify novel, distinct nonlinear associations between preoperative hemoglobin value and postoperative complications. We found that the odds of transfusion flattened notably when the level was above $135 \mathrm{~g} / \mathrm{L}$, an association that was consistent across all values of important confounders. This inflection point for transfusion was seen for both sexes. The World Health Organization classifies anemia based on sex, ${ }^{45}$ whereas international consensus experts recommend that hemoglobin values be considered independently of sex $;{ }^{46}$ our findings support the 


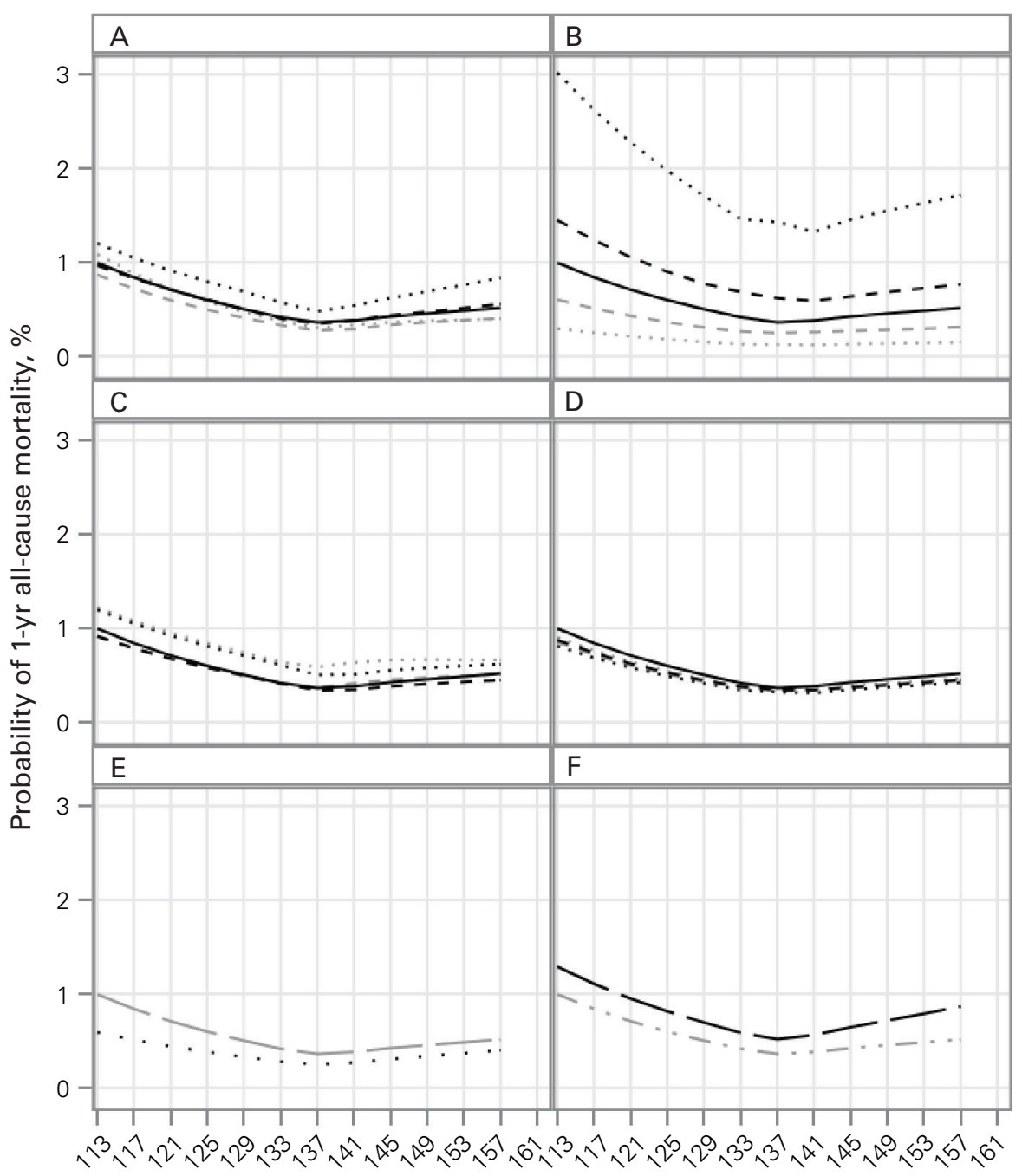

Hemoglobin level before arthroplasty, g/L

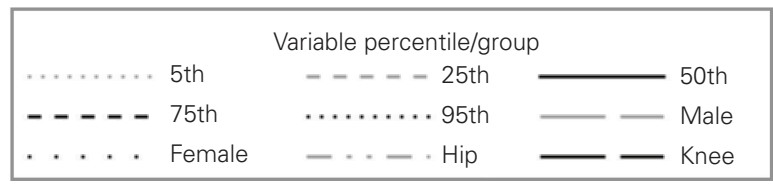

Fig. 5. Association between preoperative hemoglobin level and probability of 1-year all-cause mortality by age (A), Hospital-patient One-year Mortality Risk score (B), estimated glomerular filtration rate (C), duration of surgery (D), sex (E) and joint (F). All results are adjusted for the covariables presented in Table 2.

latter. Furthermore, the data suggest that the approach to preoperative hemoglobin testing and optimization could be stratified at $135 \mathrm{~g} / \mathrm{L}$ (a value higher than typically considered a "normal" threshold) and that, in some cases, type and cross may not be required above this threshold.

We also found robust nonlinear associations between hemoglobin level and postdischarge complications. Unplanned 30-day emergency department visit, unplanned 30-day hospital readmission and 1-year allcause mortality all showed a U-sshaped association, with the lowest probability of adverse outcome approximating 135-140 g/L. Although this finding may have been confounded by causes of chronic hypoxemia (such as smoking, obstructive sleep apnea or obesity hypoventilation syndrome) that can lead to both polycythemia and increased adverse outcomes after discharge, critical care use was not increased in the setting of higher hemoglobin values. With sleep apnea and hypoventilation, one would expect a similar causal pathway to exist between early in-hospital adverse events and longer-term adverse events. Future prospective research with detailed measurement of these 


\begin{tabular}{|c|c|c|c|c|c|c|c|c|}
\hline Study & Cohort & Design & $\begin{array}{l}\text { Single } \\
\text { centre }\end{array}$ & $\begin{array}{l}\text { No. of } \\
\text { patients }\end{array}$ & $\begin{array}{l}\text { Hemoglobin } \\
\text { level } \\
\text { categorized }\end{array}$ & Outcome & $\begin{array}{l}\text { Adjusted } \\
\text { for } \\
\text { covariables }\end{array}$ & $\begin{array}{l}\text { Association of } \\
\text { hemoglobin level } \\
\text { with outcome, OR } \\
\text { (95\% Cl) }\end{array}$ \\
\hline \multirow[t]{4}{*}{ Gu et al.., ${ }^{18} 2020$} & TJA & Cohort & No & 293043 & Yes & $\begin{array}{l}\text { Postoperative } \\
\text { complication }\end{array}$ & Yes & $\begin{array}{l}\text { Hip } 6.2 \text { (5.7-6.8), } \\
\text { knee 5.2 (4.8-5.6) }\end{array}$ \\
\hline & & & & & & Death & Yes & $\begin{array}{l}\text { Hip } 3.4(2.0-5.7), \\
\text { knee } 3.0(1.7-5.1)\end{array}$ \\
\hline & & & & & & Transfusion & Yes & $\begin{array}{l}\text { Hip } 8.7(8.0-9.6), \\
\text { knee } 9.3(8.6-10.2)\end{array}$ \\
\hline & & & & & & Reoperation & Yes & $\begin{array}{l}\text { Hip } 1.5 \text { (1.2-1.9), } \\
\text { knee } 1.5(1.1-1.9)\end{array}$ \\
\hline \multirow[t]{3}{*}{ Lu et al., ${ }^{19} 2017$} & TJA* & Case-control & No & 9480 & Yes & $\begin{array}{l}\text { Postoperative } \\
\text { complication }\end{array}$ & Yes & $1.45(1.24-1.70)$ \\
\hline & & & & & & Death & Yes & $2.18(1.09-4.36)$ \\
\hline & & & & & & $\begin{array}{l}\text { Increased length of } \\
\text { stay }\end{array}$ & Yes & $1.02(0.73-1.31)$ \\
\hline \multirow[t]{3}{*}{$\begin{array}{l}\text { Chamieh et al., }{ }^{20} \\
2016\end{array}$} & TKA* & Cohort & No & 34661 & Yest & Myocardial infarction & No & No \\
\hline & & & & & & Cardiac arrest & No & No \\
\hline & & & & & & Death & No & No \\
\hline $\begin{array}{l}\text { Jørgensen et } \\
\text { al., } 2015\end{array}$ & /TKA & Matched & No & 5400 & Yes & Cancer within $1 \mathrm{yr}$ & Yes & $0.94(0.51-1.73)$ \\
\hline \multirow[t]{2}{*}{$\begin{array}{l}\text { Liodakis et al., } 22 \\
2015\end{array}$} & $\begin{array}{l}\text { Revision } \\
\text { hip/knee } \\
\text { arthroplasty* }\end{array}$ & Cohort & No & 5068 & Yes & $\begin{array}{l}\text { Postoperative } \\
\text { complication }\end{array}$ & Yes & Yes \\
\hline & & & & & & $\begin{array}{l}\text { Increased length of } \\
\text { stay }\end{array}$ & Yes & Yes \\
\hline Viola et al., ${ }^{4} 2015$ & TJA & Case-control & Yes & 13563 & Yes & $\begin{array}{l}\text { Postoperative } \\
\text { complication }\end{array}$ & Yes & 2.11 \\
\hline \multirow[t]{2}{*}{ Jans et al., ${ }^{17} 2014$} & TJA, fast-track & Cohort & No & 5165 & Yes & 90-d readmission & Yes & $1.4(1.1-1.9)$ \\
\hline & & & & & & Length of stay $>5 d$ & Yes & $2.5(1.9-3.4)$ \\
\hline $\begin{array}{l}\text { Jämsen et al., }{ }^{23} \\
2013\end{array}$ & TJA, age $>75 \mathrm{yr}$ & Cohort & Yes & 1998 & Yes & Survival & Yes & Yes \\
\hline $\begin{array}{l}\text { O'Malley et al., }{ }^{5} \\
2012\end{array}$ & THA* & Cohort & No & 4281 & Yes & $\begin{array}{l}\text { Postoperative } \\
\text { complication }\end{array}$ & Yes & Yes \\
\hline \multirow[t]{2}{*}{$\begin{array}{l}\text { Greenky et al., }{ }^{24} \\
2012\end{array}$} & TJA & Cohort & Yes & 15772 & Yes & Infection & No & Yes \\
\hline & & & & & & Death & No & No \\
\hline $\begin{array}{l}\text { Bozic et al.. }{ }^{25} \\
2012\end{array}$ & TJA, Medicareł & Cohort & No & 83011 & Yes & Infection & Yes & Yes \\
\hline \multirow[t]{2}{*}{$\begin{array}{l}\text { Mantilla et al., }{ }^{26} \\
2011\end{array}$} & TJA & Case-control & Yes & 782 & No§ & Death & Yes & No \\
\hline & & & & & & Myocardial infarction & Yes & No \\
\hline \multicolumn{9}{|c|}{$\begin{array}{l}\mathrm{Cl}=\text { confidence interval; } \mathrm{OR}=\text { odds ratio; } \mathrm{THA}=\text { total hip arthroplasty; } \mathrm{TJA}=\text { total joint arthroplasty; } \mathrm{TKA}=\text { total } \text { knee arthroplasty. } \\
{ }^{*} \text { Used National Surgical Quality Improvement Program data. } \\
\text { TUsing } 4 \text { levels. } \\
\text { †Anemia assignment based on diagnostic code. } \\
\text { \$Hemoglobin measures analyzed as a linear term. }\end{array}$} \\
\hline
\end{tabular}

risk factors is required. In the interim, these findings highlight to clinicians that supranormal hemoglobin values may necessitate a review of underlying risk factors; to researchers the importance of avoiding the categorization of continuous variables in analysis to identify nonlinear associations and maximize power; ${ }^{47}$ and to administrators and payers that, as payment models across the United States and Canada have shifted toward bundle payment, ${ }^{48}$ these results suggest that preoperative hemoglobin values should be considered for case-mix adjustment in future bundle models.

\section{Limitations}

Several potential weaknesses should be kept in mind when interpreting the study's results. First, the study was capable of measuring the association between hemoglobin level and various outcomes in patients undergoing hip and knee arthroplasty, but not causation. This issue regarding association versus causation is key since it would influence any effect that preoperative hemoglobin optimization could have on postoperative outcomes. Second, comorbidities in this cohort, as gauged by the Charlson Comorbidity Index 
score, were notably low $;^{29}$ this may have been due to comorbidity undercounting by administrative data codes. ${ }^{49}$ This is especially relevant in our population, since less than $5 \%$ of patients had been admitted to hospital in the previous year, which means that comorbidities had to have been coded at the time of the elective procedure in order to have been counted for the study.

Third, the external generalizability of the results remains to be tested in future studies using other population-based databases. However, findings from other studies reporting on arthroplasty outcomes from ICES ${ }^{2,50}$ are compatible with studies of North American, European and Austral-Asian cohorts. ${ }^{5,18,51,52}$ Fourth, the ICES data do not accurately capture medications given to patients during the hospital stay (or peroperatively). Thus, we could not accurately test the effect of the introduction of tranexamic acid use in arthroplasty procedures in this cohort. However, it is of interest that year of surgery over the study period (which includes the introduction of tranexamic acid into routine use in arthroplasty [20122014]) did not influence outcome after other covariables were accounted for.

Last, a substantial part of our cohort was excluded owing to missing hemoglobin levels in OLIS. Patient loss owing to lack of coverage from OLIS can be classified as missing completely at random since it is primarily due to patient location (i.e., whether or not the laboratory at which patients had any preoperative laboratory testing was captured in OLIS). Since outcomes (namely, patient survival) in hip and knee arthroplasty are extremely homogeneous throughout Ontario, ${ }^{53}$ the risk of systemic bias due to this issue is minimal.

\section{Conclusion}

Preoperative hemoglobin level was independently associated with risk of red cell transfusion, postoperative critical care admission, unplanned 30-day emergency department visit, unplanned 30-day hospital readmission and 1-year all-cause mortality after hip and knee arthroplasty. These associations were frequently nonlinear. Hemoglobin levels below $135 \mathrm{~g} / \mathrm{L}$ were associated with a notable and progressive increased risk of requiring a blood transfusion peroperatively. This finding could act as a patient risk stratification tool and should be considered when devising algorithms to account for case-mix in bundle payment allowances.

Affiliations: From the Division of Orthopaedic Surgery, The Ottawa Hospital, Ottawa, Ont. (Grammatopoulos, Beaulé); the Faculty of Medicine, University of Ottawa, Ottawa, Ont. (Grammatopoulos, Beaulé); the Department of Anesthesiology and Pain Medicine, University of Ottawa, Ottawa, Ont. (McIsaac); the Clinical Epidemiology Program, The Ottawa Hospital Research Institute, Ottawa, Ont. (McIsaac, van Walraven); the Department of Epidemiology and Clinical Medicine, University of Ottawa, Ottawa, Ont. (McIsaac, van Walraven); and ICES, University of Ottawa, Ottawa, Ont. (van Walraven).
Competing interests: George Grammatopoulos reports consulting fees from Formus Labs, outside the submitted work. Paul Beaulé reports grants from Zimmer Biomet and DePuy Synthes/Johnson \& Johnson, and personal fees from MicroPort, MatOrtho, Zimmer Biomet, Medacta and Corin, outside the submitted work. No other competing interests were declared.

Contributors: All authors designed the study, acquired and analyzed the data, wrote and critically revised the manuscript, and gave final approval of the article to be published.

Content licence: This is an Open Access article distributed in accordance with the terms of the Creative Commons Attribution (CC BYNC-ND 4.0) licence, which permits use, distribution and reproduction in any medium, provided that the original publication is properly cited, the use is noncommercial (i.e., research or educational use), and no modifications or adaptations are made. See: https://creativecommons. org/licenses/by-nc-nd/4.0/.

Funding: This research did not receive any specific grant from funding agencies in the public, commercial or not-for-profit sectors.

\section{References}

1. Singh JA, Yu S, Chen L, et al. Rates of total joint replacement in the United States: future projections to 2020-2040 using the National Inpatient Sample. 7 Rheumatol 2019;46:1134-40.

2. Hip and knee replacements in Canada: CJRR report. Ottawa: Canadian Institute for Health Information; 2019.

3. Zagra L. Advances in hip arthroplasty surgery: What is justified? EFORT Open Rev 2017;2:171-8.

4. Viola J, Gomez MM, Restrepo C, et al. Preoperative anemia increases postoperative complications and mortality following total joint arthroplasty. 7 Artbroplasty 2015;30:846-8.

5. O'Malley NT, Fleming FJ, Gunzler DD, et al. Factors independently associated with complications and length of stay after hip arthroplasty: analysis of the National Surgical Quality Improvement Program. F Arthroplasty 2012;27:1832-7.

6. Spahn DR. Anemia and patient blood management in hip and knee surgery. Anesthesiology 2010;113:482-95.

7. Bisbe E, Castillo J, Sáez M, et al. Prevalence of preoperative anemia and hematinic deficiencies in patients scheduled for elective major orthopedic surgery. Transfus Altern Transfus Med 2008;10:166-73.

8. Sehat KR, Evans R, Newman J. Hidden blood loss following hip and knee arthroplasty: correct management of blood loss should take hidden loss into account. 7 Bone foint Surg Br 2004;86:561-5.

9. Sehat KR, Evans R, Newman J. How much blood is really lost in total knee arthroplasty? Correct blood loss management should take hidden loss into account. Knee 2000;7:151-5.

10. Yue C, Kang P, Yang P, et al. Topical application of tranexamic acid in primary total hip arthroplasty: a randomized double-blind controlled trial. 7 Arthroplasty 2014;29:2452-6.

11. Lee QJ, Chang WYE, Wong YC. Blood-sparing efficacy of oral tranexamic acid in primary total hip arthroplasty. 7 Arthroplasty 2017; 32:139-42.

12. Wei W, Wei B. Comparison of topical and intravenous tranexamic acid on blood loss and transfusion rates in total hip arthroplasty. $\mathcal{F}$ Arthroplasty 2014;29:2113-6.

13. Choi YJ, Kim SO, Sim JH, et al. Postoperative anemia is associated with acute kidney injury in patients undergoing total hip replacement arthroplasty: a retrospective study. Anesth Analg 2016;122:1923-8.

14. Shander A, Knight K, Thurer R, et al. Prevalence and outcomes of anemia in surgery: a systematic review of the literature. Am $7 \mathrm{Med}$ 2004;116:58S-69S.

15. Yeh JZY, Chen JY, Razak HRBA, et al. Preoperative haemoglobin cut-off values for the prediction of post-operative transfusion in total knee arthroplasty. Knee Surg Sports Traumatol Arthrosc 2016;24:3293-8. 
16. Kasivisvanathan R, Ramesh V, Rao Baikady R, et al. Preoperative anaemia is associated with increased allogeneic pack red cell transfusion in revision hip and knee joint arthroplasty: a retrospective analysis of 5387 patients over a 10-year period at a single high volume centre. Transfus Med 2016;26:271-7.

17. Jans Ø, Jørgensen C, Kehlet H, et al. Role of preoperative anemia for risk of transfusion and postoperative morbidity in fast-track hip and knee arthroplasty. Transfusion 2014;54:717-26.

18. Gu A, Malahias MA, Selemon NA, et al. Increased severity of anaemia is associated with 30 -day complications following total joint replacement. Bone foint 7 2020;102-B:485-94.

19. Lu M, Sing DC, Kuo AC, et al. Preoperative anemia independently predicts 30-day complications after aseptic and septic revision total joint arthroplasty. 7 Arthroplasty 2017;32:S197-201.

20. Chamieh JS, Tamim HM, Masrouha KZ, et al. The association of anemia and its severity with cardiac outcomes and mortality after total knee arthroplasty in noncardiac patients. F Arthroplasty 2016;31:766-70.

21. Jørgensen CC, Jans $\varnothing$, Kehlet H, et al. Preoperative anaemia and newly diagnosed cancer 1 year after elective total hip and knee arthroplasty. Vox Sang 2015;109:62-70.

22. Liodakis E, Bergeron SG, Zukor DJ, et al. Perioperative complications and length of stay after revision total hip and knee arthroplasties: an analysis of the NSQIP database. 7 Artbroplasty 2015;30:1868-71.

23. Jämsen E, Puolakka T, Eskelinen A, et al. Predictors of mortality following primary hip and knee replacement in the aged: a single-center analysis of 1,998 primary hip and knee replacements for primary osteoarthritis. Acta Orthop 2013;84:44-53.

24. Greenky M, Gandhi K, Pulido L, et al. Preoperative anemia in total joint arthroplasty: Is it associated with periprosthetic joint infection? Clin Orthop Relat Res 2012;470:2695-701.

25. Bozic KJ, Lau E, Kurtz S, et al. Patient-related risk factors for postoperative mortality and periprosthetic joint infection in Medicare patients undergoing TKA. Clin Orthop Relat Res 2012;470:130-7.

26. Mantilla CB, Wass CT, Goodrich KA, et al. Risk for perioperative myocardial infarction and mortality in patients undergoing hip or knee arthroplasty: the role of anemia. Transfusion 2011;51:82-91.

27. Zhao LP, Kolonel LN. Efficiency loss from categorizing quantitative exposures into qualitative exposures in case-control studies. Am 7 Epidemiol 1992;136:464-74.

28. Richards J, Brown A, Homan C. The data quality study of the Canadian Discharge Abstract Database. Statistics Canada International Symposium series: Proceedings. Ottawa: Statistics Canada; 2002.

29. Charlson ME, Pompei P, Ales KL, et al. A new method of classifying prognostic comorbidity in longitudinal studies: development and validation. 7 Chronic Dis 1987;40:373-83.

30. Quan H, Sundararajan V, Halfon P, et al. Coding algorithms for defining comorbidities in ICD-9-CM and ICD-10 administrative data. Med Care 2005;43:1130-9.

31. Schneeweiss S, Wang PS, Avorn J, et al. Improved comorbidity adjustment for predicting mortality in Medicare populations. Health Serv Res 2003;38:1103-20.

32. Ma QQ, Fan XD, Li T, et al. Short-and long-term prognostic value of hyponatremia in patients with acute coronary syndrome: a systematic review and meta-analysis. PLoS One 2018;13:e0193857.

33. Zhou XY, Chen HL, Ni SS. Hyponatremia and short-term prognosis of patients with acute pulmonary embolism: a meta-analysis. Int 7 Cardiol 2017;227:251-6.

34. Sun L, Hou Y, Xiao Q, et al. Association of serum sodium and risk of all-cause mortality in patients with chronic kidney disease: a metaanalysis and systematic review. Sci Rep 2017;7:15949.
35. Kuo SC, Kuo PJ, Rau CS, et al. Hyponatremia is associated with worse outcomes from fall injuries in the elderly. Int 7 Environ Res Public Health 2017;14:460.

36. Zilberberg MD, Exuzides A, Spalding J, et al. Epidemiology, clinical and economic outcomes of admission hyponatremia among hospitalized patients. Curr Med Res Opin 2008;24:1601-8.

37. Waikar SS, Mount DB, Curhan GC. Mortality after hospitalization with mild, moderate, and severe hyponatremia. Am 7 Med 2009;122: 857-65.

38. Matsushita K, Van der Velde M, Astor B, et al.; Chronic Kidney Disease Prognosis Consortium. Association of estimated glomerular filtration rate and albuminuria with all-cause and cardiovascular mortality in general population cohorts: a collaborative meta-analysis. Lancet 2010;375:2073-81.

39. McIsaac DI, Wong CA, Bryson GL, et al. Association of polypharmacy with survival, complications, and healthcare resource use after elective noncardiac surgery: a population-based cohort study. Anesthesiology 2018;128:1140-50.

40. van Walraven C. The Hospital-patient One-year Mortality Risk score accurately predicted long-term death risk in hospitalized patients. 7 Clin Epidemiol 2014;67:1025-34.

41. Casey G, van Walraven C. Prognosticating with the Hospitalized Patient 1-year Mortality Risk Score using information abstracted from the medical record. 7 Hosp Med 2017;12:224-30.

42. van Walraven C, McAlister FA, Bakal JA, et al. External validation of the Hospital-patient One-year Mortality Risk (HOMR) model for predicting death within 1 year after hospital admission. CMAf 2015; 187:725-33.

43. van Walraven C, Rodic S, McCudden C. Factors associated with zinc levels in hospitalized patients: an observational study using routinely collected data. 7 Trace Elem Med Biol 2020;61:126540.

44. Levey AS, Stevens LA, Schmid CH, et al.; CKD-EPI (Chronic Kidney Disease Epidemiology Collaboration). A new equation to estimate glomerular filtration rate. Ann Intern Med 2009;150:604-12.

45. Haemoglobin concentrations for the diagnosis of anaemia and assessment of severity. Geneva: World Health Organization; 2011.

46. Muñoz M, Acheson AG, Auerbach M, et al. International consensus statement on the peri-operative management of anaemia and iron deficiency. Anaesthesia 2017;72:233-47.

47. van Walraven C, Hart RG. Leave 'em alone - why continuous variables should be analyzed as such. Neuroepidemiology 2008;30:138-9.

48. Miller DC, Ye Z, Gust C, et al. Anticipating the effects of accountable care organizations for inpatient surgery. FAMA Surg 2013;148: 549-54.

49. Quan H, Parsons GA, Ghali WA. Validity of information on comorbidity derived from ICD-9-CCM administrative data. Med Care 2002; 40:675-85.

50. Ravi B, Pincus D, Croxford R, et al. Patterns of pre-operative opioid use affect the risk for complications after total joint replacement. Sci Rep 2021;11:22124.

51. American Academy of Orthopaedic Surgeons; American Association of Orthopaedic Surgeons. Annual report 2021. The eighth annual report of the AJRR on hip and knee arthroplasty. Available: https:// connect.ajrr.net/2021-ajrr-annual-report (accessed 2021 Jan. 7).

52. National Joint Registry. 18th annual report 2021. Available: https:// reports.njrcentre.org.uk/Portals/0/PDFdownloads/NJR\%20 18th\%20Annual\%20Report\%202021.pdf (accessed 2021 Jan. 7).

53. McIsaac D, Lavallée LT, van Walraven C. A retrospective assessment of prognostication in 456,685 patients undergoing elective major non-cardiac surgery. Can 7 Anaesth 2017;64:908-18. 